\title{
Production of transgenic Hypericum perforatum plants via particle bombardment-mediated transformation of novel organogenic cell suspension cultures
}

\author{
G. Franklin ${ }^{\mathrm{a}}$, M. Oliveira ${ }^{\mathrm{b}}$, A.C.P Dias ${ }^{\mathrm{a}, *}$ \\ ${ }^{a}$ Departamento de Biologia, Universidade do Minho, Campus de Gualtar, 4710-057 Braga, Portugal \\ ${ }^{\mathrm{b}}$ Instituto de Biologia Experimental e Tecnológica (IBET), Av. da República, Quinta do Marquês, 2781-901 Oeiras, Lisboa, Portugal
}

Received 4 January 2007; received in revised form 22 February 2007; accepted 23 February 2007

Available online 12 March 2007

\begin{abstract}
We have developed particle bombardment-mediated transformation procedure for Hypericum perforatum L. (St. John's wort), an important medicinal species that remains highly recalcitrant towards Agrobacterium-mediated transformation. Among the major transformation techniques evaluated in the present study (Agrobacterium tumefaciens-, A. rhizogenes- and biolistics-mediated), particle-bombardment-mediated gene transfer was found to be the most successful one. GUS positive cells were obtained from organogenic nodules bombarded with the plasmid vector pCAMBIA1301 encoding an intron-containing $\beta$-glucuronidase (gusA) and hygromycin phosphotransferase (hpt) genes. After 3 months of continuous selection of bombarded nodules with $20 \mathrm{mg}^{-1}$ hygromycin, transgenic hygromycin-resistant callus cultures and subsequently transgenic plants were produced. PCR analysis of DNA isolated from GUS positive plants showed the presence of both gusA and hpt genes. Southern blot analysis confirmed the transgene integration and revealed diverse copy numbers and insertion sites. The data presented here demonstrate for the first time $H$. perforatum can be efficiently transformed via particle bombardment of organogenic cell suspension. Our results open the possibility of using particle bombardment-mediated transformation to elucidate biosynthetic pathways and to improve secondary metabolite production in $H$. perforatum.
\end{abstract}

(C) 2007 Elsevier Ireland Ltd. All rights reserved.

Keywords: Hypericum perforatum; Organogenic nodular structures; Agrobacterium transformation; GUS gene; Particle bombardment

\section{Introduction}

Hypericum perforatum L. (HP), commonly known as St. John's wort is an important medicinal plant used in the treatment of several pathologies since ancient times. The clinical efficacies of the HP extracts in the therapy of mild to moderate depressions have been confirmed in recent studies $[1,2]$. Many other important pharmaceutical properties of HP including antiviral [3], anticancer [4], neuroprotective [5] and

Abbreviations: AS, acetosyringone; AVG, aminoethoxyvinylglycine; BA, 6-benzylaminopurine; BHT, butylated hydroxytoluene; FDA, fluoresein diacetate; GUS, ß-glucuronidase; HP, Hypericum perforatum; hpt, hygromycin phosphotransferase; IAA, indole-3-acetic acid; IBA, indole-3-butyric acid; MS, Murashige and Skoog; NAA, naphthaleneacetic acid; ONS, organogenic nodular structures; PGR, plant growth regulator

* Corresponding author. Fax: +35153678980.

E-mail address: acpdias@bio.uminho.pt (A.C.P. Dias). antioxidant [6] activities have also been reported. Since treating humans and animals with HP extracts does not show any serious adverse side effects [7], use of this medicinal herb has increased dramatically during the past decade. Today, HP products are one of the top selling herbal medicines worldwide which are sold in the USA as a dietary supplement, while in Europe as anti-depressive agents [8]. These important pharmaceutical properties of the HP secondary metabolites have been the main thrust for the enormous research with cell cultures focused at present [9-13].

The use of plant cell and tissue cultures for the large-scale production of secondary metabolites has so far achieved only limited success due to the low and unreliable yields of the secondary products. Although significant improvements in product yields have been achieved through conventional biochemical approaches and the manipulation of the culture and process factors, the reproducibility of results is still a major concern [14]. Metabolic engineering is envisaged as an 
effective and powerful tool for improving the biosynthesis of therapeutically useful compounds in medicinal plants $[15,16]$. As the pharmacological activities of HP extract are largely attributed to hypericin and hyperforin which are exclusively produced in this species, improving their production is an important target for genetic manipulation. This goal could not be achieved so far because of the poor knowledge about their biosynthesis and also due to the absence of transformation systems. Establishment of procedures for genetic transformation of HP would be useful for studying the biochemical and gene expression profiles of the biosynthetic pathways, and in metabolic engineering. Hence, there is an immediate need for establishing a transformation system for HP.

Among the several gene transfer techniques currently in practice, Agrobacterium tumefaciens-mediated transformation is the most efficient and commonly used technique in plant genetic engineering. On the other hand, hairy root cultures established by Agrobacterium rhizogenes-mediated transformation often sustain stable productivity in hormone-free culture conditions resulting in large amounts of secondary metabolites accumulation [17]. Particle-bombardment technique has been successfully used in the genetic transformation of a wide variety of plant species including many that are not amenable to Agrobacterium-mediated transformation [18] and become the second most widely used technique for plant transformation [19].

In the current investigation, we evaluated the efficiency of $A$. tumefaciens, A. rhizogenes and particle-bombardment techniques for transformation of HP. We report the successful genetic transformation of HP via particle-bombardment-mediated gene transfer for the first time.

\section{Materials and methods}

\subsection{Sources of explants and plant regeneration}

Various plant parts such as leaf blade, petiole, stem and root segments excised from the aseptic seedlings of HP var. Helos (purchased from Richters, Goodwood, Canada) were used as differentiated explants. The regeneration protocol adopted for these explants has been described elsewhere [20]. Briefly, explants obtained from 15-day-old aseptic seedlings were cultured on MS medium [21] containing $0.5 \mathrm{mg}^{-1}$ benzylaminopurine (BA) and $1.0 \mathrm{mg} \mathrm{l}^{-1}$ indole-3-acetic acid (IAA) and maintained at $16 \mathrm{~h}$ photoperiod.

As a source of novel organogenic nodule (ONS) explants, cell suspension culture was established from compact callus induced from HP (var. Helos) leaf explants as described earlier [22]. The established suspension cultures possessed morphologically distinct white and green cell types. The later cell type developed into ONS of about 1-3 mm in diameter (Fig. 1A) which resembled raspberry fruit (Fig. 1B). These ONS were filtered from the culture with a steel mesh screen (\#40, Sigma, Barcelona) and cultured separately in Erlenmeyer flasks containing MS liquid medium supplemented with $0.475 \mathrm{mg}^{-1}$ NAA on a rotary shaker at $80 \mathrm{rpm}$. For maintenance and multiplication, $10 \mathrm{ml}$ of the suspension (medium + ONS) was transferred to Erlenmeyer flasks $(250 \mathrm{ml})$ each containing $70 \mathrm{ml}$ of medium and subcultured once in every 30 days. MS media supplemented with various concentrations of BA $(0,0.1$, $0.5,1.0$ and $\left.2.0 \mathrm{mg} \mathrm{l}^{-1}\right)$ and NAA $\left(0.0\right.$ or $\left.0.1 \mathrm{mg} \mathrm{l}^{-1}\right)$ were tested for plant regeneration from ONS. Culture plates inoculated with ONS were maintained in the dark until the onset of callus or shoot formation and thereafter transferred to photoperiod conditions.

Combination of $3 \%(\mathrm{w} / \mathrm{v})$ sucrose and $0.8 \%(\mathrm{w} / \mathrm{v})$ bacteriological grade agar (Sigma, Barcelona) was common to all solid media. The $\mathrm{pH}$ was adjusted to 5.8 (unless otherwise mentioned) before autoclaving at $1.0 \mathrm{~kg} \mathrm{~cm}^{-2}$ for $15 \mathrm{~min}$ in both liquid and solid media. For callus/shoot induction, disposable Petri dishes containing 20-25 ml of solidified medium were inoculated with 5-10 explants, sealed with parafilm and cultured. All the cultures were incubated at $25{ }^{\circ} \mathrm{C}$ under photoperiodic $(16 \mathrm{~h})$ conditions under fluorescent bulbs (Fluora, Germany) at the light intensity of $25 \mu \mathrm{mol} \mathrm{s}{ }^{-1} \mathrm{~m}^{-2}$ unless otherwise mentioned. Half-strength MS medium with $0.5 \mathrm{mg} \mathrm{l}^{-1}$ indole-3-butyric acid (IBA) was used for rooting.

\subsection{Optimization of hygromycin selection}

To determine the appropriate concentration of hygromycin for the selection of transformants, explants were cultured on their respective regeneration medium, i.e. $\mathrm{MS}+1.0 \mathrm{mg} \mathrm{l}^{-1}$ $\mathrm{BA}+0.1 \mathrm{mg} \mathrm{l}^{-1} \mathrm{NAA}$ for ONS (medium optimized in the
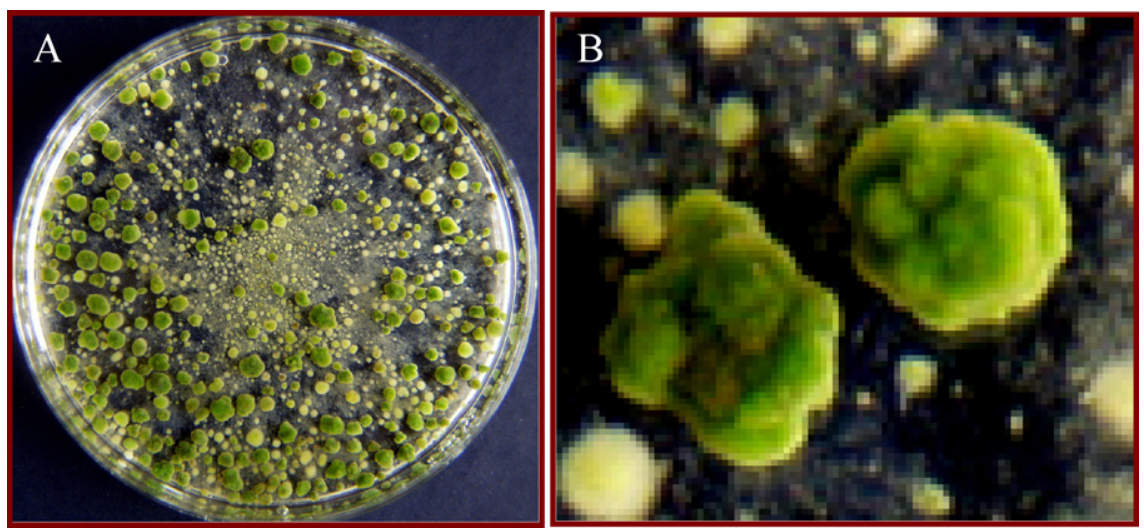

Fig. 1. (A) Organogenic cell suspension culture showing ONS explants. (B) Close-up view of ONS showing raspberry-like appearance. 
Table 1

Regeneration of shoots from onganogenic nodules on MS medium supplemented with various concentrations of plant growth regulators after 30 days of culture initiation

\begin{tabular}{llll}
\hline $\begin{array}{l}\text { PGR } \\
\left(\mathrm{mg} \mathrm{l}^{-1}\right)\end{array}$ & NAA & $\begin{array}{l}\text { Nodules } \\
\text { regenerating }(\%)\end{array}$ & $\begin{array}{l}\text { Mean no. shoots } \pm \\
\text { S.D. per explant }\end{array}$ \\
\hline BA & 0.0 & 0 & \\
\hline 0.0 & 0.0 & 10 & 0 \\
0.1 & 0.0 & 20 & $4.5 \pm 0.9 \mathrm{a}$ \\
0.5 & 0.0 & 40 & $7.8 \pm 1.5 \mathrm{~b}$ \\
1.0 & 0.0 & 55 & $8.4 \pm 1.8 \mathrm{~b}$ \\
2.0 & 0.1 & 0 & $3.4 \pm 1.2 \mathrm{a}$ \\
0.0 & 0.1 & 60 & 0 \\
0.1 & 0.1 & 70 & $11.3 \pm 2.3 \mathrm{~b}$ \\
0.5 & 0.1 & 90 & $25.6 \pm 4.4 \mathrm{~d}$ \\
1.0 & 0.1 & 75 & $7.5 \pm 1.8 \mathrm{~b}$ \\
2.0 & & & $\mathrm{c}$ \\
\hline
\end{tabular}

Values followed by the same letters are not significantly different $(P>0.05$, Kruskal-Wallis test).

present study, Table 1) and $\mathrm{MS}+0.5 \mathrm{mg}^{-1} \mathrm{BA}+1.0 \mathrm{mg} \mathrm{l^{-1 }}$ IAA for leaf blade, petiole, stem and root segments (medium optimized previously [20]) supplemented with different concentrations of hygromycin $(0.0,5.0,15.0,20.0,30.0$ and $50.0 \mathrm{mg} \mathrm{l}^{-1}$ ). The ONS tissues were maintained in dark, whereas all other explants were maintained under photoperiod. Explants were maintained for 40 days with frequent subculture onto fresh medium once in every 10 days. The viability of explants was monitored by visual observation and fluorescein diacetate staining during each subculture.

\subsection{Plasmid vector, Agrobacterium strains and culture}

The plasmid pCAMBIA1301 (CAMBIA, Australia) containing the selectable $h p t$ gene that encodes hygromycin phosphotransferase and the reporter gusA gene disrupted by catalase intron that favors the expression only in eukaryotic cells was used in all the transformation experiments. Both these genes are driven by CaMV $35 \mathrm{~S}$ promoter, and are cloned in opposite orientation (Fig. 2). For Agrobacterium-mediated transformation, pCAMBIA1301 was transferred to the disarmed A. tumefaciens strains LBA4404 and EHA105 using $\mathrm{CaCl}_{2}$ method [23]. A. tumefaciens strains were maintained in LB medium supplemented with $25 \mathrm{mg} \mathrm{l}^{-1}$ rifampicin and $50 \mathrm{mg}^{-1}$ kanamycin. Wild type $A$. rhizogenes strains A4 and LBA9402 were grown in MYA and YMB media, respectively.

Single Agrobacterium (tumefaciens/rhizogenes) colony was inoculated into $5.0 \mathrm{ml}$ of appropriate liquid bacterial culture medium augmented with suitable antibiotics if required and incubated at $28{ }^{\circ} \mathrm{C}$ in a rotary shaker at $200 \mathrm{rpm}$ for $12-16 \mathrm{~h}$. Subsequently, $0.5 \mathrm{ml}$ of grown bacterial broth was transferred to $250 \mathrm{ml}$ Erlenmeyer flask containing $100 \mathrm{ml}$ of bacterial culture medium and maintained under similar conditions. When the bacterial culture reached the optical density (OD) of 0.8-1.0 at $660 \mathrm{~nm}$, bacteria were spun down using a tabletop centrifuge (Eppendorf, USA) at $4000 \mathrm{rpm}$ and re-suspended in the vir gene induction medium [1× $\mathrm{AB}$ salts [24], $2 \mathrm{mM}$ $\mathrm{NaPO}_{4}, 50 \mathrm{mM}$ 2-morpholinoethanesulfonic acid (pH 5.6), $0.5 \%$ glucose and $100 \mu \mathrm{M}$ acetosyringone (AS)].

\subsection{Agrobacterium-mediated transformation}

Leaf blade, petiole, stem and root segment explants were precultured in $\mathrm{MS}+0.5 \mathrm{mg} \mathrm{l}^{-1} \mathrm{BA}+1.0 \mathrm{mg} \mathrm{l}^{-1} \mathrm{IAA}$ medium and ONS were precultured in $\mathrm{MS}+1.0 \mathrm{mg} \mathrm{l}^{-1} \mathrm{BA}+$ $0.1 \mathrm{mg} \mathrm{l}^{-1} \mathrm{NAA}$ medium for $24 \mathrm{~h}$. Precultured explants were infected with the bacterial suspension for 5, 10, 20 and $30 \mathrm{~min}$, blot-dried and transferred onto co-cultivation (CC) medium (regeneration medium $+200 \mu \mathrm{M}$ AS, $\mathrm{pH}$ 5.2) for co-cultivation. To check the efficacy of antioxidants and ethylene inhibitor on T-DNA transfer, the co-cultivation medium was supplemented with $10.0 \mathrm{mg} \mathrm{l}^{-1}$ butylated hydroxytoluene (BHT), $400 \mathrm{mg} \mathrm{l}^{-1}$ cysteine, $100 \mathrm{mg} \mathrm{l}^{-1} \mathrm{AgNO}_{3}$ and 5.0 $\mathrm{mg} \mathrm{l}^{-1}$ aminoethoxyvinylglycine (AVG) in different experiments. Explants co-cultivated with Agrobacterium (tumefaciens/rhizogenes) were thoroughly washed with sterilized distilled water to remove Agrobacterium contamination and transferred to regeneration medium under selection (with $20 \mathrm{mg} \mathrm{l}^{-1}$ hygromycin and $250 \mathrm{mg} \mathrm{l}^{-1}$ ticarcillin clavulanate) or without selection (only with ticarcillin for bacteria elimination).

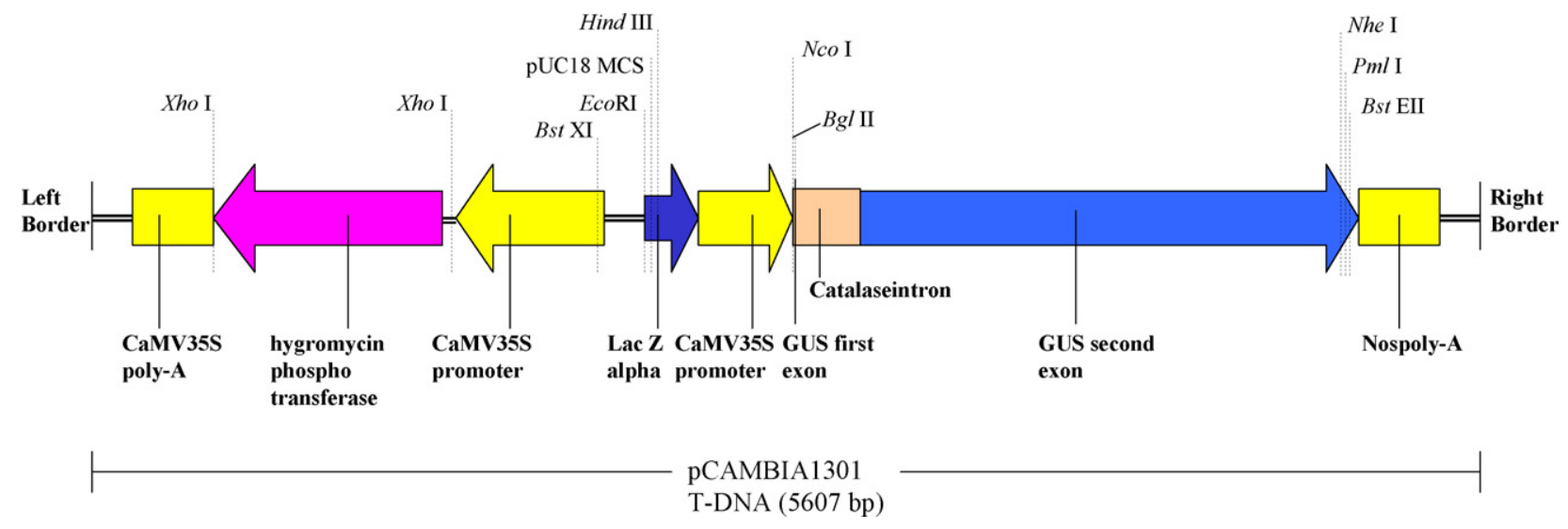

Fig. 2. T-DNA of pCAMBIA1301 showing restriction sites. 
2.5. Plasmid isolation, precipitation of plasmid DNA onto gold particles and preparation of explants for

bombardment

Plasmid DNA (pCAMBIA1301) was isolated from the $E$. coli strain (DH5 $\alpha$ ) using the Wizard ${ }^{\mathbb{R}}$ plus midipreps DNA purification system (Promega, USA) and precipitated onto 1.0- $\mu \mathrm{m}$ gold particles (Bio-Rad, USA) following standard procedures. Briefly, the following components were orderly added to an Eppendorf tube $(1.5 \mathrm{ml})$ containing $87.5 \mu \mathrm{l}$ of gold particles $(7 \mathrm{mg}$ in $50 \%$ glycerol) in agitation: $5 \mu \mathrm{l}$ of plasmid DNA $(1 \mu \mathrm{g} / \mu \mathrm{l}), 87.5 \mu \mathrm{l}$ of $2.5 \mathrm{M} \mathrm{CaCl}_{2}$ and $35 \mu \mathrm{l}$ of $100 \mathrm{mM}$ spermidine. The mixture was rested on ice for $10 \mathrm{~min}$ before centrifugation at $6000 \mathrm{rpm}$ in a microfuge. The supernatant was discarded and the pellet was resuspended in $100 \mu \mathrm{l}$ ethanol (100\%). Just prior to loading the particle bombardment apparatus, the particles were vortexed for a few seconds to disperse any clumps. For each bombardment, $10 \mu \mathrm{l}$ of DNA-gold suspension containing $700 \mu \mathrm{g}$ gold particles associated with $0.5 \mu \mathrm{g}$ plasmid DNA was spread and air-dried onto a macrocarrier.

Based on the results with Agrobacterium-mediated transformation, only ONS explants were selected for further experiments with particle bombardment. Approximately $4 \mathrm{~h}$ before bombardment, ONS were harvested from the suspension culture and placed in the liquid osmotic medium (MS $+1.0 \mathrm{mgl}^{-1}$ $\mathrm{BA}+0.1 \mathrm{mg} \mathrm{l}^{-1} \mathrm{NAA}+34 \mathrm{~g}^{-1}$ mannitol $+34 \mathrm{~g} \mathrm{l}^{-1}$ sorbitol). For each bombardment assay, $1.0 \mathrm{ml}$ of ONS along with osmotic medium was poured at the center ( $3 \mathrm{~cm}$ diameter) of a sterile round Whatman filter paper disk until excess liquid was absorbed. Each disk was then carefully transferred to Petri dish $(100 \mathrm{~mm})$ containing $20 \mathrm{ml}$ of solid osmotic medium before bombardment.

\subsection{Particle bombardment}

The bombardment chamber of a particle delivery system (PDS-1000/He, Bio-Rad) was evacuated at a pressure of 28 in. of mercury. Explants were bombarded with DNA-coated gold particles discharged with different rupture disk pressures (650, 900 and $1100 \mathrm{psi}$ ) from 9.0 and $13.0 \mathrm{~cm}$ flying distances (distance between stopping screen and target tissue) once. To check whether repeated bombardments can improve transformation efficiency, ONS were also bombarded twice (first and second hits from 9.0 and $13.0 \mathrm{~cm}$, respectively) both with same rupture disk pressures $(650,900$ or $1100 \mathrm{psi})$. Four hours after bombardment, the ONS were transferred onto regeneration medium. After 2 days incubation on regeneration medium, half of the bombarded explants were transferred to selection medium (MS $+1.0 \mathrm{mg} \mathrm{l}^{-1}$ $\mathrm{BA}+0.1 \mathrm{mg} \mathrm{l}^{-1} \mathrm{NAA}+20.0 \mathrm{mg}^{-1}$ hygromycin $+250 \mathrm{mg} \mathrm{l}^{-1}$ ticarcillin clavulanate) and the other half were transferred to regeneration medium supplemented with $250 \mathrm{mg} \mathrm{l}^{-1}$ ticarcillin clavulanate. The broad spectrum antibiotic, ticarcillin clavulanate was added in the media to prevent contamination.

\subsection{Regeneration of transgenic plants}

Calluses with shoot initials developed from the ONS explants on regeneration medium with or without selection were transferred to MS basal medium with hygromycin $\left(20 \mathrm{mg}^{-1}\right)$ for shoot elongation. Elongated shoots $(3-5 \mathrm{~cm})$ were excised from the explant and transferred to Baby Food Jars containing $50 \mathrm{ml}$ of half-strength MS medium supplemented with $0.5 \mathrm{mg} \mathrm{l}^{-1}$ indole-3-butyric acid (IBA) and $20 \mathrm{mg} \mathrm{l}^{-1}$ hygromycin for root induction. For hardening, culture bottles containing rooted plants were filled with sterile distilled water and incubated at room temperature $\left(26^{\circ} \mathrm{C}\right)$. After 2 days, the plants were removed from the medium, washed thoroughly in running tap water to remove the traces of rooting medium and planted in JIFFY-7 (Lisbon, Portugal) plant propagation systems and covered with polyethylene bags. The plants were acclimatized by reducing the humidity through making holes in the polyethylene bags and exposing to sunlight gradually for 1 week. Hardened plants were transferred to garden pots containing soil: compost $(1: 1)$, irrigated regularly with tap water and grown in a growth chamber (Fitotron, Sanyo) under photoperiod at $26{ }^{\circ} \mathrm{C}$ day-night temperature with $70 \%$ relative humidity.

\subsection{Enzymatic histochemical GUS assay}

GUS assay was performed periodically (after 2, 10 and 90 days) for explants from various experiments to monitor transformation. The percentage of initial transient expression was calculated as the number of explants showing blue spots divided by the total number of explants assayed and multiplied by hundred. The presence of the GUS gene in the putative transformants was detected histochemically following the procedure of Jefferson et al. [25]. Briefly, leaves and roots from plants obtained under early and late selection were incubated in a solution containing $100 \mathrm{mM} \mathrm{NaH}_{2} \mathrm{PO}_{4}$ buffer, $\mathrm{pH} 7.5,50 \mathrm{mM}$ each of $\mathrm{K}_{3} \mathrm{FeCn}_{6}$ and $\mathrm{K}_{4} \mathrm{FeCn}_{6}, 1 \mathrm{mM}$ 5-bromo-4-chloro-3indolyl $\beta$-D-glucuronide cyclohexylammonium salt (Sigma) and $0.1 \%$ Triton-X 100 overnight at $37^{\circ} \mathrm{C}$ and cleared in $70 \%$ ethanol.

\subsection{PCR analysis of putative transgenic plants}

Genomic DNA from the plants was isolated using DNeasy plant mini kit (QIAGEN, Germany). The gusA gene fragment was amplified using forward primer sequence 5'GATCGCGAAAACTGTGGAAT $3^{\prime}$ and reverse primer sequence 5'TGAGCGTCGCAGAACATTAC $3^{\prime}$. The forward and reverse primer sequences for the $h p t$ gene amplification were $5^{\prime}$ ATTTGTGTACGCCCGACAGT3' and $5^{\prime}$ GGATATGTCCTGCGGGTAAA $3^{\prime}$, respectively. The reaction mixture contained $50 \mathrm{ng}$ of genomic DNA, $2.0 \mu \mathrm{l}$ of each primer ( $5 \mathrm{pmol}), 0.5 \mu \mathrm{l}$ of dNTP mix (2.5 mM each), $2.5 \mu$ l of PCR buffer, $0.25 \mu l$ of Taq DNA polymerase $(5 \mathrm{U} / \mu \mathrm{l})$ and the volume was adjusted to $25 \mu \mathrm{l}$ with sterile distilled water. The PCR conditions included hot start at $94{ }^{\circ} \mathrm{C}$ for $4 \mathrm{~m}$, followed by 30 cycles of denaturation $\left(94{ }^{\circ} \mathrm{C}, 1 \mathrm{~m}\right)$, annealing $\left(55^{\circ} \mathrm{C}, 2 \mathrm{~m}\right)$ and extension $\left(72{ }^{\circ} \mathrm{C}, 2 \mathrm{~m}\right)$, with a final extension of $10 \mathrm{~m}$ at $72{ }^{\circ} \mathrm{C}$. PCR amplified products were resolved in $0.8 \%$ agarose gel with ethidium bromide. 


\subsection{Southern blot analysis}

For Southern blot analysis, $20 \mu \mathrm{g}$ aliquot of genomic DNA was digested with the restriction endonuclease EcoR I, electrophoresed on $1.0 \%$ agarose gel and transferred onto a Hybond nylon membrane (Amersham, UK). The pCAMBIA1301 DNA was used as the positive control. Prehybridization and hybridization were performed, respectively, for 3 and $16 \mathrm{~h}$ in church buffer $(250 \mathrm{mM}$ sodium phosphate buffer $(\mathrm{pH}$ 7.2), $1 \% \mathrm{BSA}, 7 \% \mathrm{SDS}$ and $1 \mathrm{mM}$ EDTA) at $55^{\circ} \mathrm{C}$. PCR fragment of the gusA gene $(1.3 \mathrm{~kb})$ was labeled with $\alpha-\left[{ }^{32} \mathrm{P}\right]$ dCTP (Amersham, UK) using Prime-a-Gene ${ }^{\circledR}$ labeling kit (Promega, USA) and used as probe. Hybridized blots were washed twice with $2 \times \mathrm{SSC}+0.1 \% \mathrm{SDS}$ each for $15 \mathrm{~min}$ and with $0.1 \times \mathrm{SSC}+0.1 \% \mathrm{SDS}$ for $5 \mathrm{~min}$ at $55^{\circ} \mathrm{C}$. The blots were exposed to the imaging screen for $12 \mathrm{~h}$ and scanned in a Phosphorimager (Bio-Rad, USA).

\subsection{Data analysis}

For all the treatments, 3 independent experiments were done each with at least 10 samples. All the data were analyzed statistically. Regeneration from ONS under different combinations of plant growth regulators (PGRs) was analyzed by Kruskal-Wallis test followed by Dunn's multiple comparison test. The effect of rupture disk pressures and target distances on transformation was analyzed by one-way analysis of variance (ANOVA). The homogeneity of variance was tested by Cochran's test. Post hoc comparisons were made with the HSD Tukey test. All analyses were performed using GraphPad Prism version 4.00 for Windows (GraphPad Software, San Diego, California, USA).

\section{Results and discussion}

\subsection{Organogenic cell suspension cultures as source of explants}

Several regeneration protocols have been reported for HP so far [26-29]. Recently, we have developed an efficient genotypeindependent regeneration system from several explant tissues such as leaves, root segments and stem segments [20]. In spite of the robustness of this regeneration protocol, we were unable to achieve HP transgenic shoots from Agrobacterium transformations since the bacteria failed to infect any of the differentiated explants (leaf blade, petiole, stem and root segment). The recalcitrance of these explants to Agrobacterium infection might be due to the presence of hypericin and hyperforin, which are known antibacterial compounds [30]. Since, these compounds are only found in the differentiated tissues, in the present work, we have tested in comparison the efficiency of Agrobacterium and particle bombardmentmediated transformation in a novel explant, the green nodular structures produced from cell suspension cultures. Vardapetyan et al. [31] first reported the accumulation of globular structures in the later stages of HP cell suspension cultures which resembled raspberry fruit. However, the utility of these structures in regeneration and transformation of HP has only now been demonstrated.

\subsection{BA concentration and light conditions affected plant regeneration from $O N S$}

Plant regeneration from the ONS explants was affected by the BA concentration in a dose-dependent manner. There was a positive relationship between the percentage of ONS explants showing regeneration and BA concentration until $1.0 \mathrm{mg} \mathrm{l}^{-1}$ (Table 1). Addition of NAA $\left(0.1 \mathrm{mg} \mathrm{l}^{-1}\right)$ along with BA further increased the percentage of regeneration, with an optimum concentration of $1.0 \mathrm{mg} \mathrm{l}^{-1} \mathrm{BA}$ and $0.1 \mathrm{mg} \mathrm{l}^{-1}$ NAA. Our previous study with differentiated explants also suggested that for callus induction and subsequent regeneration, HP needs a high cytokinin/auxin ratio [20]. In the absence of growth regulators or with NAA as sole PGR, no shoot induction was observed. Incubation in continuous dark until formation of calluses (1-2 weeks) is critical for plant regeneration from ONS, as the explants turned brown and showed delayed callusing when cultured under photoperiod at the beginning of culture. On the other hand, this initial dark treatment was not essential for regeneration from differentiated explants [20].

\subsection{HP explants are highly sensitive to hygromycin}

When the explants were cultured on optimal regeneration medium supplemented with different concentrations of hygromycin, all the explants died within 10 days on medium containing hygromycin concentrations higher than $15 \mathrm{mg} \mathrm{l}^{-1}$. Only $5 \%$ of the explants formed callus on medium containing $15 \mathrm{mg}^{-1}$ hygromycin. Hence, $20 \mathrm{mg} \mathrm{l}^{-1}$ of hygromycin was considered optimum for the selection of transformants. Hygromycin selection was originally applied for the transformation of monocotyledonous species but it also works efficiently for recalcitrant dicotyledonous species [32-35].

\subsection{Agrobacterium did not infect differentiated tissues}

Susceptibility of the plant cell towards Agrobacterium infection is the foremost requirement for T-DNA transfer. In the present study, all the tested differentiated explants (leaf blade, petiole, stem and root segment) were found to be resistant to Agrobacterium and T-DNA transfer did not occur. None, out of hundred explants from each treatment assayed for GUS showed blue spots regardless of selective or non-selective conditions. Hence, we did not continue the experiments with these explants further. There are several reports of high necrosis and poor survival rate of target plant tissues during the process of Agrobacterium-mediated T-DNA transfer in other species [3638] as a consequence of plant's hypersensitive reaction to Agrobacterium infection. In the case of HP, differentiated tissues such as leaves, stem, flowers and roots generally contain antimicrobial secondary metabolites such as hypericin and hyperforin, which can be induced in response to biotic elicitation [39] suggesting that the inability of Agrobacterium 
to grow and infect these explants could be due to antimicrobial activity of these compounds.

\subsection{Agrobacterium infected ONS in a low frequency in the presence of butylated hydroxy toluene (BHT)}

All the ONS explants turned brown within one day of cocultivation with A. tumefaciens/rhizogenes. Browning of explants co-cultivated with $A$. tumefaciens became more intense under selection pressure eventually, resulted in necrosis within 10 days and none of the explants showed transient gus A expression or callus formation. However, under non-selective conditions, all the ONS co-cultivated with A. tumefaciens and A. rhizogenes regained their normal growth within 5 days and produced calluses as the control. Staining of cells from these calluses using fluoresein diacetate 10 days after Agrobacterium infection confirmed $100 \%$ cell viability. In spite of the browning occurred after Agrobacterium co-cultivation, the cells managed to survive upon subculture in medium with no selection pressure. Moreover, genomic DNA isolated from the explants co-cultivated with $A$. tumefaciens did not show any fragmentation indicates that the incompatibility of Agrobacterium-mediated transformation in HP is not due to necrosis induced by programmed cell death as reported for other species [40].

Among the one hundred ONS explants assayed for GUS after co-cultivation with A. tumefaciens strain EHA105 on $\mathrm{CC}+\mathrm{BHT}$ medium, two explants exhibited GUS foci when cultured on medium without selection. Similarly, one of the explants infected with the other A. tumefaciens strain LBA4404 also showed GUS foci suggesting that $A$. tumefaciens can infect HP under special conditions but in a very low frequency. These positive results could be due to the use of a strong anti-oxidant combined with the novel explant (ONS) which are devoid of organ-specific compounds such as hypericin. ONS explants cocultivated in the presence of other antioxidants and ethylene inhibitors did not show any GUS foci indicate that BHT is more effective in scavenging harmful reactive molecular species. It seems that BHT can be used as a potential antioxidant in other recalcitrant plant species also. Even though the calluses obtained from ONS under non-selective conditions after cocultivating with Agrobacterium regenerated shoots as the control, none of them were transgenic. Hence, they were not analyzed further.

A number of species previously considered recalcitrant are now efficiently transformed by supplementing antioxidants [38,41] and ethylene inhibitors [42-44] in the co-cultivation medium. This is mainly because of the fact that oxidative burst or ethylene production during plant-Agrobacterium interaction could be suppressed by these scavengers. However, in our case the tested antioxidants and ethylene inhibitor in the cocultivation medium did not prevent browning indicating that the browning may be connected to the cellular defense responses. Recently, it was demonstrated that plants can modulate their gene expression in response to Agrobacterium infection and that Agrobacterium can actually trigger the plant defense machinery [45]. Changes in the phenolic profile and darkening of HP suspended cells after elicitation with fungal biomass was also reported [46]. Hence, the browning response of HP when infected with Agrobacterium could be somewhat connected to the modulation of the phenylpropanoid pathway.

\subsection{Rupture disk pressure and the number of bombardments affected the recovery of transgenic plants}

In the present study, the initial transient expression level of ONS explants bombarded once (either 9.0 or $13.0 \mathrm{~cm}$ target distance) and twice (from both 9.0 and $13.0 \mathrm{~cm}$ target distances) remained similar. However, the callus induction frequencies were significantly reduced $(P<0.05)$ in ONS bombarded twice under selective and non-selective conditions (Fig. 3A and B). This might be attributed to the extent of mechanical injury created by gold particles and cell death when the same tissues were bombarded twice. When bombarded once, callus induction was higher in explants hit by gold particles released from 1100 psi rupture disks than 650 and 900 psi rupture disks under selection in both 9.0 and $13.0 \mathrm{~cm}$ flying distances (Fig. 3B, $P<0.05$ ). This variation in callus induction frequencies between rupture disk pressures may be attributed to the dissimilar penetration rate of the gold particles and eventually to the DNA delivery, as the cells received the DNA only can survive under selection. Effective penetration of the target plant tissue by the microprojectiles carrying the DNA is essential for successful gene delivery. The flying distance and rupture disc pressure are obviously affecting the speed of the microprojectiles when reaching explant surface [47]. Rupture
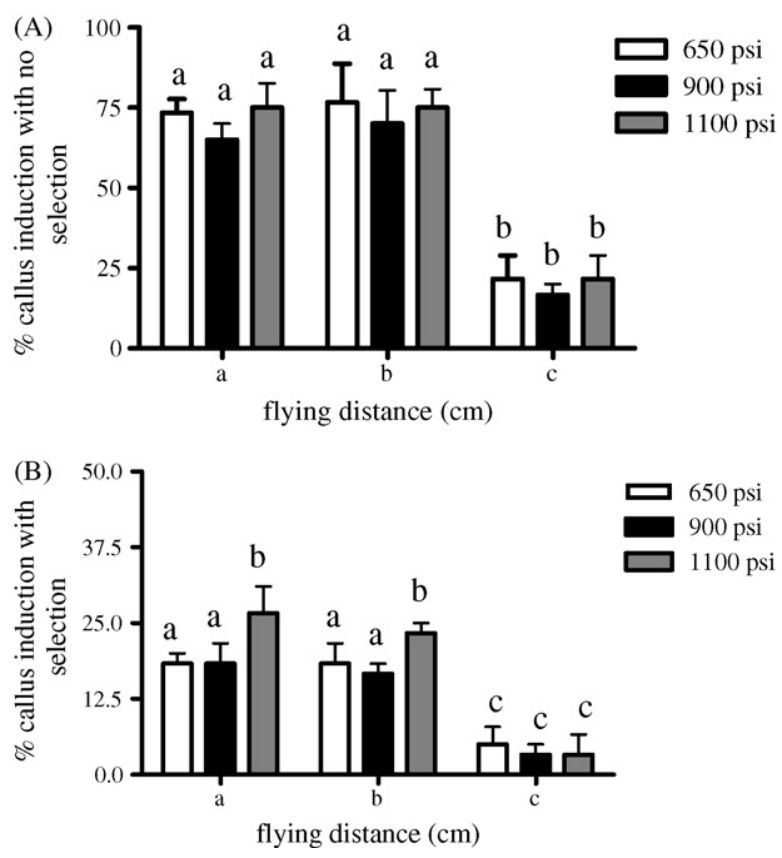

Fig. 3. Graphical presentation of the effect of rupture disk pressures $(650,900$ and $1100 \mathrm{psi}$ ) and number of shots (a, single shot from $9.0 \mathrm{~cm}$ flying distance, $\mathrm{b}$, single shot from $13.0 \mathrm{~cm}$ flying distance and c-two shots; one from $9.0 \mathrm{~cm}$ and the other from $13.0 \mathrm{~cm}$ flying distances) on DNA delivery. (A) Callus induction frequency of ONS 45 days after bombardment under non-selective condition. (B) Callus induction frequency of ONS 80 days after bombardment under selection. Error bars with different letters are statistically different $(P<0.05)$. 
Table 2

Effect of the number of bombardments, rupture disk pressures and flying distances on HP transformation using ONS explants under early (ES) and late (LS) selection

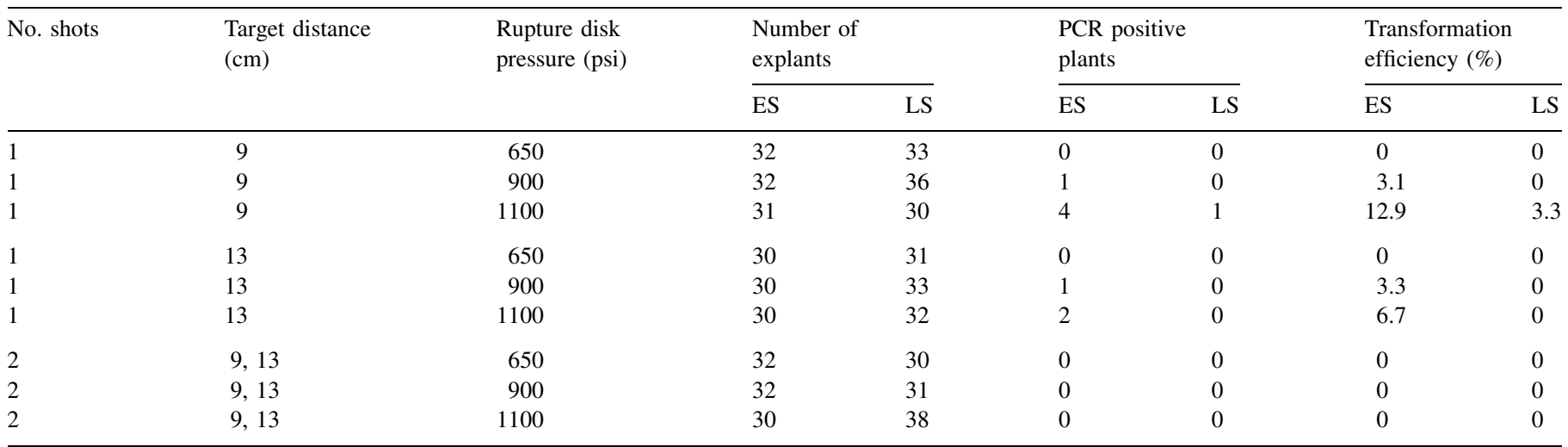

disk pressures and flying distances did not have any effect on plant regeneration under both early as well as late selection. However, when verified by PCR, the combination of $9.0 \mathrm{~cm}$ flying distance with 1100 psi rupture disk pressure resulted in more transgenic plants than other treatments under both early and late selection (Table 2). This result indicates that the higher acceleration we tested to drive the microprojectiles was the most beneficial factor for HP transformation.

\subsection{Timing of hygromycin selection critically affected transformation efficiency}

Timing of hygromycin selection of the bombarded explants critically affected transformation efficiency (Table 2). When the explants were transferred to selection medium 2 days after bombardment, only after 10 weeks about $25 \%$ of explants produced callus from each plate (Fig. 4A). These calluses regenerated shoot buds after 6-9 months of bombardment, but in a very low frequency (3.0 shoots/callus). Eight shoots rooted on half-strength MS medium supplemented with $0.5 \mathrm{mg} \mathrm{l}^{-1}$ IBA and $20 \mathrm{mg}^{-1}$ hygromycin (Fig. 4F).

Under non-selective (late selective) condition, ONS proliferated during the first 2 weeks of culture, and callus began to appear 4 weeks after bombardment similar to the control. Two weeks later, about $90 \%$ of these explants had formed yellowish calluses with a characteristic red pigmentation (Fig. 4B), 55\% of which regenerated shoots (Fig. 4C). Subsequently after 2-3 months, when transferred to selection medium, these cultures produced several albinos along with green shoots (Fig. 4D). In rice, late selection resulted in the formation of chimeric callus lines [48] while in colonial bent grass it produced albino plantlets [49]. Repeated selection of cultures with shoots finally resulted in the regeneration of uniform green shoots (Fig. 4E). Five green shoots produced roots on rooting medium with $20 \mathrm{mg}^{-1}$ hygromycin.

PCR analysis of the genomic DNA isolated from all the eight rooted plants obtained from early selection had the expected fragments of gus A $(1.3 \mathrm{~kb})$ and $h p t(0.8 \mathrm{~kb})$ genes amplified (Table 2). Whereas, among the five rooted plants obtained from late selection, one had the expected fragments (Table 2). As expected, the transgenes were not amplified in the control plant.
These results indicate that the early selection is efficient in producing transgenic plants without escape vice versa in late selection.

All the rooted plants were subjected to acclimatization process. However, a total of seven plants (R4 and R5 from early selection and R1, R2, R3, R6 and R7 from late selection) could be successfully hardened (Fig. 4G) and established in garden pots (Fig. 4H) as described earlier [20] for further analyses.

\subsection{GUS histochemical evidence for transformation}

Transient gus A gene expression $48 \mathrm{~h}$ after bombardment was used as an initial indicator of the efficiency of gene transfer (Fig. 5A). DNA delivery frequencies ranged from 45 to $75 \%$ of GUS-positive explants per bombarded plate. This high variability in transient gene expression between plates is probably due to the variations in the degree of the gold particles coating with the DNA as reported earlier [50], or to the aleatory distribution and penetration of gold particles, or even to variations in physiological status of the ONS. In all the GUSpositive explants, the foci were observed in the clustered multicell aggregates rather than single cells (Fig. 5A, inset). Individual GUS focus could be seen even after 10 days of bombardment (Fig. 5B) eventually indicating stable expression.

When the explants with slow-growing calluses obtained from early selection were subjected to GUS assay, blue staining was confined only to the newly formed calluses (Fig. 5C) indicating that growth of non-transformed tissues was completely prevented by this early selection. When the explants with callus and shoots, developed under non-selective conditions, were subjected to histochemical GUS test, blue staining was found in the calluses and in small parts of the shoots (Fig. 5D) indicating chimeric gus A gene expression.

All the plants established in the pots after early selection (R4 and R5) and one out of five from late selection (R7) stably expressed the gusA gene in roots (Fig. 5E) and leaves (Fig. 5F). Since genes interrupted with an intron will only express after intron splicing, and the non-transformed HP explants tested for GUS expression were negative (Fig. 5F right), the integration of the transgene in these three plants could be confirmed. 

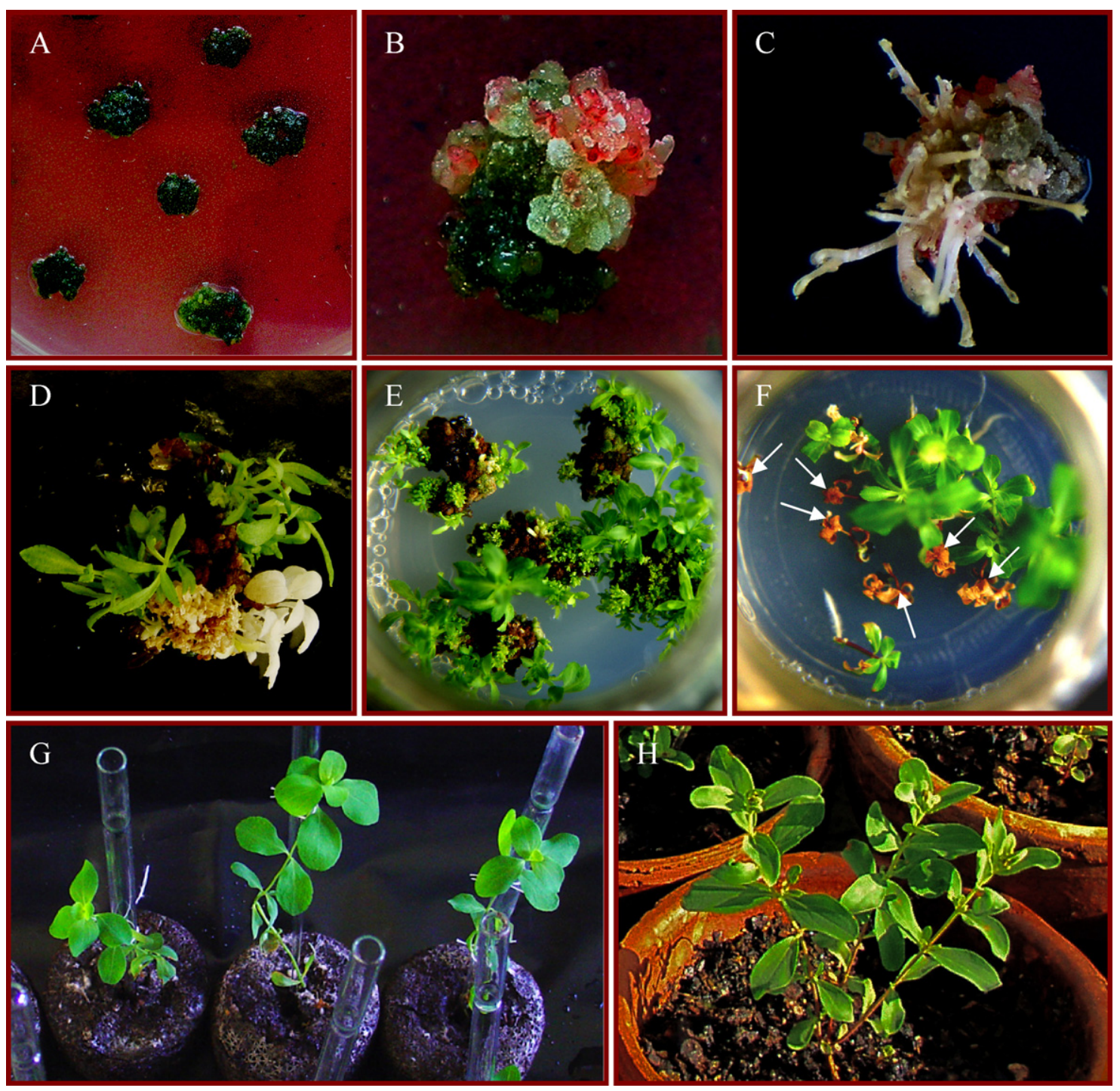

Fig. 4. Particle bombardment-mediated transformation of HP with pCAMBIA1301. (A) Callus development from bombarded explants after 10 weeks on selection medium. (B) Quick proliferation of yellowish calluses possessing characteristic red pigmentation from bombarded explants under non-selective conditions after 6 weeks of incubation under dark. (C) Shoots regenerating from explants under non-selective conditions after 8 weeks of dark incubation. (D) Cultures with albino and green shoots upon late selection (3 months) of cultures initially maintained under nonselective condition. (E) Cultures with uniform green plants after 3 subsequent selections. (F) Rooting of regenerated shoots under selection showing death of shoots (arrows) susceptible to hygromycin and root initiation from resistant ones after 12 days. (G) Hardening of putatively transformed HP plants. (H) A transgenic plant established in pot. (For interpretation of the references to colour in this figure legend, the reader is referred to the web version of the article).

\subsection{Molecular evidence for transgene integration in the transgenic plants}

Southern blot analysis of the seven potted plants (R1-R7) is shown in Fig. 6. Among these, the three plants which were positive for GUS assay and PCR (R4, R5 and R7) had hybridization signals in the Southern blot which confirmed the presence of the gus gene in these transgenic HP plants. No hybridization signal was detected in genomic DNA from nontransformed control plant.

Southern blot analysis also revealed that the gus A gene had integrated into the HP genome of different individuals with diverse copy numbers and insertion sites. The observed band pattern indicates that the three transgenic plants were derived from three independent transformation events. The difference in the banding pattern between R4 and R5 is a point for different transformation events, although both shoots derived from the same callus. Each sample showed a different band pattern depending on where the T-DNA integrated in the plant genome, since only one Eco RI site was present in the T-DNA (Fig. 2). The Southern pattern showed eight or more fragments, thus representing hybrid molecules containing DNA from both the vector and the plant genome, and demonstrating transgene integration in different loci (eight to ten sites). The strong bands in the lanes of R4 and R7 probably indicate multiple copies of the transgene integrated as concatemers.

Biolistics-mediated transformation generally results in high copy number transgene integration [51] which may lead to 


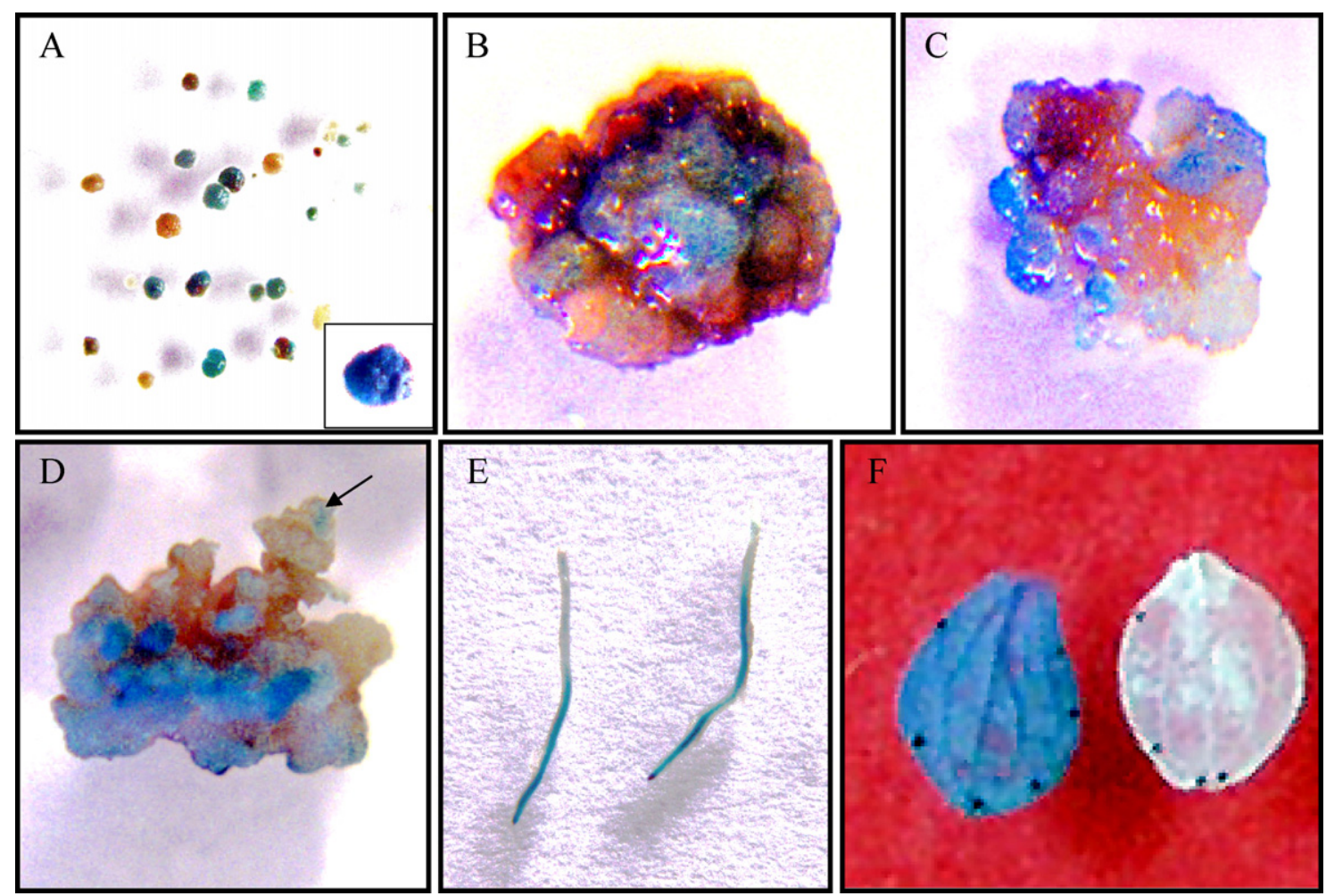

Fig. 5. Expression of gusA gene during the development of transgenic HP plants from the ONS. (A) A plate of ONS explants bombarded with pCAMBIA1301 DNA using 1100 psi rupture disk with $9.0 \mathrm{~cm}$ flying distance showing many explants with transient GUS expression and others with no expression (inset, close up view of an ONS showing clustered and indistinguishable GUS foci). (B) A GUS positive explant showing several GUS foci 10 days after bombardment indicating stable transgene expression, close up view. (C) An ONS explant showing GUS activity confined to the newly formed calluses under early selection after bombardment. (D) An explant subjected to hygromycin selection only after 3 months of bombardment showing GUS activity in the callus as well as in a portion of a shoot (arrow) indicating chimeric gene expression. (E) Root segments of a transgenic HP plant showing GUS activity. (F) Leaf of a transgenic HP plant showing GUS activity and control leaf in the right; note the characteristic feature of HP leaves, the presence of black spots indicating hypericin glands. (For interpretation of the references to gus A gene expression in this figure legend, the reader is referred to the web version of the article).

transgene silencing. From the Southern analysis of the transgenic HP plants, we found no correlation between transgene copy number and expression, since the transgenic HP plants stably expressing GUS are multicopy for GUS gene.

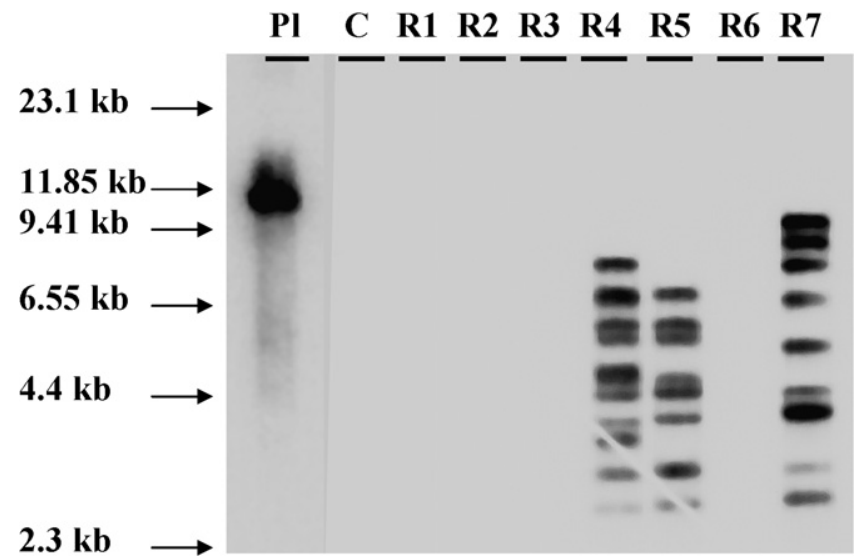

Fig. 6. Southern blot analysis of DNA isolated from leaves of non-transformed control plant and seven hygromycin resistant plants established in pots. (Pl) pCAMBIA1301 DNA showing hybridization signal at $11.8 \mathrm{~kb}$. (C) Non-transformed control plant had no hybridization signal. (R1, R2, R3 and R6) Plants had no hybridization signal indicating late selection resulted in high frequency of escapes upon rooting on hygromycin. (R4 and R5) Plants with hybridization signal indicating early selection is efficient in eliminating escapes. (R7) Transgenic plant obtained from late selection.
Craig et al. [52] also demonstrated the lack of correlation between gene copy and/or insertion site number with gene expression levels in biolistically transformed potato lines. Similarly, transgenic rice lines that received multicopies of GUS and/or bar could express the gene(s) stably at high levels up to the R3 generation [53].

In conclusion, as the host range of Agrobacterium pose obstacles for the transformation of HP, particle bombardment can be successfully combined with the regeneration of shoots from ONS via organogenesis in producing transgenic HP plants. This lays the foundation for metabolic engineering of HP for the production of important secondary metabolites such as hypericin and hyperforin. The use of ONS as target tissue is a key factor for the recovery of transgenic HP plants in our study.

\section{Acknowledgements}

We are grateful to Dr. Richard Jefferson for providing the plasmid pCAMBIA1301 and to Dr. David Tepfer for the gift of Agrobacterium rhizogenes strains A4 and LBA9402. This work was supported by Fundação de Ciência e Tecnologia (POCTI/ AGR/40283/2001). Postdoctoral fellowship (SFRH/BPD/ 17102/2004) awarded by Fundação de Ciência e Tecnologia to G. Franklin is gratefully acknowledged. 


\section{References}

[1] Y. Lecrubier, G. Clerc, R. Didi, M. Kieser, Efficacy of St. John's wort extract WS 5570 in major depression: a double-blind, placebo-controlled trial, Am. J. Psychiatry 159 (2002) 1361-1366.

[2] V. Butterweck, Mechanism of action of St. John's wort in depression: what is known? CNS Drugs 17 (2003) 539-562.

[3] R.F. Schinazi, C.K. Chu, J.R. Babu, B. Oswald, V. Saalman, D.L. Cannon, B.F.H. Ericksson, M. Nasr, Anthraquinones as a new class of antiviral agents against human immunodeficiency virus, Antiviral Res. 13 (1990) 265-272.

[4] P. Agostinis, A. Vantieghem, W. Merlevede, A.M. Peter, Hypericin in cancer treatment: more light on the way, Int. J. Biochem. Cell Biol. 34 (2002) 221-241.

[5] B.A. Silva, A.C.P. Dias, F. Ferreres, J.O. Malva, C.R. Oliveira, Neuroprotective effect of $H$. perforatum extracts on beta-amyloid-induced neurotoxicity, Neurotoxicol. Res. 6 (2004) 119-130.

[6] B.A. Silva, F. Ferreres, J.O. Malva, A.C.P. Dias, Phytochemical and antioxidant characterization of Hypericum perforatum alcoholic extracts, Food Chem. 90 (2005) 157-167.

[7] R.D. Trautmann-Sponsel, A. Dienel, Safety of Hypericum extract in mildly to moderately depressed outpatients. A review based on data from three randomized, placebo-controlled trials, J. Affect. Disord. 82 (2004) 303-307.

[8] D. Jean, M. Pouligon, A.C. Henriot, Pharmacological activity of three commercial Hypericum perforatum preparations in mice, Phytother. Res. 20 (2006) 653-654.

[9] A.B. Kirakosyan, H.R. Vardapetyan, A.G. Charchoglyan, The content of hypericin and pseudohypericin in cell cultures of Hypericum perforatum L. (St. John's wort) and production of hypericin, Russ. J. Plant Physiol. 47 (2000) 270-273.

[10] M.A.L. Smith, H. Kobayashi, M. Gawienowski, D.P. Briskin, An in vitro approach to investigate chemical synthesis by three herbal plants, Plant Cell Tiss. Org. Cult. 70 (2002) 105-111.

[11] G. Pasqua, P. Avato, B. Monacelli, A.R. Santamaria, M.P. Argentieri, Metabolites in cell suspension cultures, calli, and in vitro regenerated organs of Hypericum perforatum cv, Topas. Plant Sci. 165 (2003) 977982.

[12] A.C.P. Dias, M.F. Ferreira, Production of phenolics by in vitro cultures of Hypericum perforatum: a case study, in: A.P. Rauter, M.E. Araujo, F.B. Palma, J. Justino, S.P. Santos (Eds.), Natural Products in the New Millennium: Prospects and Industrial Application, Kluwer Academic Publishers, Dordrecht, 2003, pp. 367-374.

[13] A.C.P. Dias, The potential of in vitro cultures of Hypericum perforatum and Hypericum androsaemum to produce interesting pharmaceutical compounds, in: Edzard Earnst (Ed.), Hypericum: The Genus Hypericum, Taylor and Francis, 2003, pp. 137-154.

[14] L.G. Zhou, J.Y. Wu, Development and application of medicinal plant tissue cultures for production of drugs and herbal medicinals in China, Nat. Prod. Rep. 23 (2006) 789-810.

[15] W. Hu, J. Zhong, Effect of bottom clearance on performance of airlift bioreactor in high-density culture of Panax ginseng cells, J. Biosci. Bioeng. 92 (2001) 389-392.

[16] T.M. Kutchan, A role for intra-and intercellular translocation in natural product biosynthesis, Curr. Opin. Plant Biol. 8 (2005) 292-300.

[17] N. Sevon, K.M. Oksman-Caldentey, Agrobacterium rhizogenes-mediated transformation: root cultures as a source of alkaloids, Planta Med. 68 (2002) 859-868.

[18] A. Kemp, J. Parker, C. Grierson, Biolistic transformation of Arabidopsis root hairs: a novel technique to facilitate map-based cloning, Plant J. 27 (2001) 367-371.

[19] A. Jahne, D. Becker, H. Lorz, Genetic engineering of cereal crop plants: a review, Euphytica 85 (1995) 35-44.

[20] G. Franklin, A.C.P. Dias, Organogenesis and embryogenesis in several Hypericum perforatum genotypes, In vitro Cell Dev. Biol. Plant 42 (2006) 324-330.

[21] T. Murashige, F. Skoog, A revised medium for rapid growth and bioassays with tobacco tissue cultures, Physiol. Plant 15 (1962) 473-497.
[22] A.C.P. Dias, R.M. Seabra, B. Andrade, F. Ferreres, M.F. Ferreira, Xanthone production in calli and suspended cells of Hypericum perforatum, J. Plant Physiol. 158 (2001) 821-827.

[23] T. Tzfira, C.S. Jensen, W. Wang, A. Zuker, B. Vinocur, A. Altman, A. Vainstein, Transgenic Populus tremula: a step-by-step protocol for its Agrobacterium-mediated transformation, Plant Mol. Biol. Rep. 15 (1997) 219-235

[24] M.-D. Chilton, T.C. Currier, S.K. Farrand, A.J. Bendich, M.P. Gordon, E.W. Nester, Agrobacterium tumefaciens DNA and PS8 bacteriophage DNA not detected in crown gall tumors, Proc. Natl. Acad. Sci. U.S.A. 71 (1974) 3672-3676.

[25] R.A. Jefferson, T.A. Kavanagh, M.W. Bevan, GUS fusions: $\beta$-glucronidase as a sensitive and versatile gene fusion marker in higher plants, EMBO J. 6 (1987) 3901-3907.

[26] F.R. Pretto, E.R. Santarem, Callus formation and plant regeneration from Hypericum perforatum leaves, Plant Cell Tiss. Org. Cult. 62 (2000) 107113.

[27] S.J. Murch, K.L. Choffe, J.M.R. Victor, T.Y. Slimmon, S. Krishnaraj, P.K Saxena, Thidiazuron-induced plant regeneration from hypocotyl cultures of St. John's wort (Hypericum perforatum cv 'Anthos'), Plant Cell Rep. 19 (2000) 576-581.

[28] S.M.A. Zobayed, P.K. Saxena, In vitro grown roots: a superior explant for prolific shoot regeneration of St. John's wort (Hypericum perforatum L. cv 'New Stem') in a temporary immersion bioreactor, Plant Sci. 165 (2003) 463-470.

[29] S.M.A. Zobayed, S.J. Murch, H.P.V. Rupasinghe, P.K. Saxena, In vitro production and chemical characterization of St. John's wort (Hypericum perforatum L. cv 'New Stem'), Plant Sci. 166 (2004) 333-340.

[30] P. Avato, F. Raffo, G. Guglielmi, C. Vitali, A. Rosato, Extracts from St John's wort and their antimicrobial activity, Phytother. Res. 18 (2004) 230-232.

[31] H.R. Vardapetyan, A.B. Kirakosyan, A.G. Charchoglyan, The kinetic regularities of the globular structures growth in cell cultures of Hypericum perforatum L., Biotechnologia 4 (2000) 53-58.

[32] P.M. Olhoft, L.E. Flagel, C.M. Donovan, D.A. Somers, Efficient soybean transformation using hygromycin B selection in the cotyledonary-node method, Planta 216 (2003) 723-735.

[33] X. Li, X.D. Wang, X. Zhao, Y. Dutt, Improvement of cotton fiber quality by transforming the acsA and acsB genes into Gossypium hirsutum L. by means of vacuum infiltration, Plant Cell Rep. 22 (2004) 691-697.

[34] M. Sujatha, M. Sailaja, Stable genetic transformation of castor (Ricinus communis L.) via Agrobacterium tumefaciens-mediated gene transfer using embryo axes from mature seeds, Plant Cell Rep. 23 (2005) 803-810.

[35] V. Kumar, K.V. Satyanarayana, S. Sarala Itty, E.P. Indu, P. Giridhar, A. Chandrashekar, G.A. Ravishankar, Stable transformation and direct regeneration in Coffea canephora P ex. Fr. by Agrobacterium rhizogenes mediated transformation without hairy-root phenotype, Plant Cell Rep. 25 (2006) 214-222.

[36] A. Mercuri, L.D. Benedetti, G. Burchi, T. Schiva, Agrobacterium mediated transformation of African violet, Plant Cell Tiss. Org. Cult. 60 (2000) 39-46.

[37] R. Chakrabarty, N. Viswakarma, S.R. Bhat, P.B. Kirti, B.D. Singh, V.L. Chopra, Agrobacterium-mediated transformation of cauliflower: optimization of protocol and development of Bt-transgenic cauliflower, J. Biosci. 27 (2002) 495-502.

[38] D.K. Das, M.K. Reddy, K.C. Upadhyaya, S.K. Sopory, An efficient leafdisk culture method for the regeneration via somatic embryogenesis and transformation of grape (Vitis vinifera L.), Plant Cell Rep. 20 (2002) 9991005.

[39] T. Sirvent, D.M. Gibson, Induction of hypericins and hyperforin in Hypericum perforatum $\mathrm{L}$. in response to biotic and chemical elicitors, Physiol. Mol. Plant Pathol. 60 (2002) 311-320.

[40] G. Hansen, Evidence of Agrobacterium-induced apoptosis in maize cells, Mol. Plant Microbe Interact. 13 (2000) 649-657.

[41] B.R. Frame, H. Shou, R.K. Chikwamba, Z. Zhang, C. Xiang, T.M. Fonger, S.E.K. Pegg, B. Li, D.S. Nettleton, D. Pei, K. Wang, Agrobacterium 
tumefaciens-mediated transformation of maize embryos using a standard binary vector system, Plant Physiol. 129 (2002) 13-22.

[42] J.-S. Han, C.K. Kim, S.H. Park, K.D. Hirschi, I.-G. Mok, Agrobacteriummediated transformation of bottle gourd (Lagenaria siceraria Standl.), Plant Cell Rep. 23 (2005) 692-698.

[43] C. Petri, N. Alburquerque, O. Perez-Tornero, L. Burgos, Auxin pulses and a synergistic interaction between polyamines and ethylene inhibitors improve adventitious regeneration from apricot leaves and Agrobacterium-mediated transformation of leaf tissues, Plant Cell Tiss. Org. Cult. 82 (2005) 105-111.

[44] E.S. Seong, K.J. Song, S. Jegal, C.Y. Yu, I.M. Chung, Silver nitrate and aminoethoxyvinylglycine affect Agrobacterium-mediated apple transformation, Plant Growth Regul. 45 (2005) 75-82.

[45] R.F. Ditt, E. Nester, L. Comai, The plant cell defense and Agrobacterium tumefaciens, FEMS Microbiol. Lett. 247 (2005) 207-213.

[46] L.F.R. Conceição, F. Ferreres, R.M. Tavares, A.C.P. Dias, Induction of phenolic compounds in Hypericum perforatum L. cells by Colletotrichum gloeosporioides elicitation, Phytochemistry 67 (2006) 149-155.

[47] R. Marchant, J.B. Power, J.A. Lucas, M.R. Davey, Biolistic transformation of rose (Rosa hybrida L.), Ann. Bot. 81 (1998) 109-114.
[48] P. Christou, T.L. Ford, The impact of selection parameters on the phenotype and genotype of transgenic rice callus and plants, Transgenic Res. 4 (1995) 44-51.

[49] M.L. Chai, K.K. Senthil, D.H. Kim, Transgenic plants of colonial bentgrass from embryogenic callus via Agrobacterium-mediated transformation, Plant Cell Tiss. Org. Cult. 77 (2004) 165-171.

[50] S.V. Sawant, P.K. Singh, R. Tuli, Pretreatment of microprojectiles to improve the delivery of DNA in plant transformation, Biotechniques 29 (2000) 246-248.

[51] C. Gao, L. Jiang, M. Folling, L. Han, K.K. Nielsen, Generation of large numbers of transgenic Kentucky bluegrass (Poa pratensis L.) plants following biolistic gene transfer, Plant Cell Rep. 25 (2006) 19-25.

[52] W. Craig, D. Gargano, N. Scotti, T.T. Nguyen, N.T. Lao, T.A. Kavanagh, P.J. Dix, T. Cardi, Direct gene transfer in potato: a comparison of particle bombardment of leaf explants and PEG-mediated transformation of protoplasts, Plant Cell Rep. 24 (2005) 603-611.

[53] A. Kohli, D. Gahakwa, P. Vain, D.A. Laurie, P. Christou, Transgene expression in rice engineered through particle bombardment: molecular factors controlling stable expression and transgene silencing, Planta 208 (1999) 88-97. 